\title{
Recruitment and group composition strategies for family-based substance misuse prevention interventions: an exploratory evaluation
}

\author{
Jeremy Segrott
}

Jeremy Segrott is a Research Fellow at DECIPHer: Centre for the Development and Evaluation of Complex Interventions for Public Health Improvement, Cardiff University, Cardiff, UK.
This work was supported by the Wales Office of Research and Development in Health and Social Care through its funding of the All Wales Alliance for Research and Development in Health and Social Care (AWARD). The author would like to thank: Cathy Weatherup, Chris Tudor-Smith and colleagues from the Welsh Government; Stephen Burgess, Hayley Collicot, Sarah Macdonald and Rachel Clark who helped run project focus groups; members of the SFP coordinating team, programme facilitators and families attending the SFP who took part in the research and helped in other ways; two referees for their helpful suggestions; and Adam Fletcher, Heather Rothwell, Simon Murphy, Sarah Morgan-Trimmer, Sarah Whitehead and Keli Komro who commented on earlier versions of the paper.

\begin{abstract}
Purpose - This paper aims to report findings from an evaluation of the Strengthening Families Programme 10-14 (UK) (SFP 10-14 UK), focusing on the strategies used to recruit families into a universal prevention intervention, the approach taken to group composition, and the experiences of participating families.

Design/methodology/approach - Methods comprised interviews with programme coordinating team members, a focus group with programme facilitators, focus groups with parents and young people, observation of programme sessions and coordinator visits to families, and analysis of programme questionnaires.

Findings - Paying attention to group composition and the needs of families with challenges holds promise in terms of reach and acceptability, delivery fidelity, enabling intended psycho-social programme processes and promoting positive changes in parenting and family communication.

Originality/value - First, the paper examines the development of strategies for recruiting participants, which has been identified as a key implementation challenge. Second, it explores approaches for managing group composition and dynamics in family-based programmes. While much has been written about the development of group norms and peer learning processes in interventions for young people, less has been written about how group dynamics work in programmes involving both parents and young people and the implications for implementation fidelity.
\end{abstract}

Keywords Prevention intervention, Recruitment, Parenting, Families, Group composition, Strengthening Families Programme 10-14, Parent, Family

Paper type Research paper

\section{Introduction}

Parents play an important role in shaping young people's attitudes towards, and their use of, alcohol and drugs (Foxcroft and Lowe, 1997; Highet, 2005) through parental drinking behaviours and role modelling, and the rules and monitoring they put in place around substance use (Garmiene et al., 2006; Moore et al., 2010). Broader parental practices and family functioning also act as protective and risk factors for young people's substance use (Shortt et al., 2007; Velleman and Templeton, 2007). Thus many parent or family-based prevention interventions have been developed which address these risk and protective factors and seek to strengthen parenting skills, family communication and pro-social rules and norms concerning alcohol (Cuijpers, 2003; Velleman, 2009).

A crucial part of the implementation of such programmes is the recruitment of parents and young people (Redmond et al., 2004), but many prevention interventions experience challenges 
in recruiting participants (Dumka et al., 1997), and the effectiveness of strategies to engage families remains an under-researched area (Skärstrand et al., 2009; Spoth et al., 2007a). Some programmes target (and recruit) families on the basis of risk or support need levels (Heinrichs et al. , 2005; Hiscock et al., 2008; Offord et al., 1998). Targeted recruitment may reach families in which young people are at higher risk of later problems, but accurately identifying and engaging such families may be challenging (Bayer et al., 2007; Hogue et al., 2002) and produce feelings of resentment and stigmatisation (Bayer et al., 2007; Wiggins et al., 2009) which act as barriers to participation. In contrast, a universal approach involves delivering interventions which are "thought to be desirable for everyone in the eligible population and are implemented with no assessment of individual risk" (Hogue et al., 2002). Such interventions can avoid stigmatisation processes, and through community-level recruitment have the potential make large-scale impacts on public health (Spoth et al., 2002; Spoth and Redmond, 2000), especially given the fact that a larger proportion of risk behaviours typically resides within the numerically greater low-risk population (Offord, 2000; Rose, 1992). However, universal programmes also encounter difficulties in recruiting families, and take-up rates are typically low (Al-Halabi Diaz et al., 2006; Redmond et al., 2004; Spoth et al., 2007a; Spoth and Redmond, 2000). Key factors which affect participation include practical barriers such as programme timing and travel arrangements (Coombes et al., 2006; Mihalic and Irwin, 2003), programme length and location (Spoth and Redmond, 2000), parents' beliefs about parenting and risk factors, including the susceptibility of their children to problematic behaviours (Spoth and Redmond, 2000), and socio-demographic characteristics such as educational background (Guyll et al., 2003; Redmond et al., 2002). Whilst universal programmes are designed for families from a range of backgrounds across a population they may nevertheless need to tailor recruitment strategies in order to ensure that certain groups, such as those with higher level needs are enabled to attend (Bayer et al., 2007; Dumka et al., 1997; Spoth et al., 2002; Spoth and Redmond, 2000). A range of approaches to increasing recruitment rates have been described in the literature, including monetary and other incentives (Heinrichs, 2006; Kumpfer, 1998), advertising and mass media campaigns (Sanders et al., 2002), removing practical barriers to attendance (such as providing assistance with travel, childcare or offering refreshments) (Spoth and Redmond, 2002), involving culturally matched recruiters (Fox et al., 2004) and engaging with influential individuals in the community to provide endorsements of programmes (Secrest et al., 2005).

The degree of targeting which recruitment strategies employ is also important because prevention programmes typically bring together groups of parents (or parent-child dyads), giving rise to complex psycho-social dynamics which may influence programme delivery and intended programme mechanisms. There is an extensive literature concerning the challenges of bringing together groups of young people with high levels of need/challenges and how this may shape group norms and peer learning processes in ways that run counter to the values and messages of the intervention they are participating in (Botvin and Griffin, 2007; Gifford-Smith et al., 2005; Gottfredson et al., 2006; Palinkas et al., 1996; Wiggins et al., 2009). Alongside the potential for targeted interventions to generate feelings of labelling and stigmatisation (Bayer et al., 2007; Dumka et al., 1997; Offord, 2000; Wiggins et al., 2009), a key concern is that bringing together groups of high-risk young people may inadvertently produce harmful effects through peer contagion. Dishion and Tipsord (2011) identify deviancy training as one of the key mechanisms through which peer contagion works, describing it as involving:

[...] the interpersonal dynamic of mutual influence during which youth respond positively to deviant talk and behaviour. As applied to peer contagion, the deviancy training process is characterised by give-and-take exchanges between friends that promote deviant actions (e.g. past stories of deviant acts, suggestions for future behaviour, what ifs), and elicit positive responses, such as laughter (p. 190).

Transmission of peer contagion may take place through individuals observing and imitating others' deviant behaviour, and by such behaviour being reinforced by group norms (Cho et al., 2005). These negative processes can have negative impacts on long-term health behaviours, such as alcohol use and smoking (Dishion and Tipsord, 2011). For instance, Dishion and Andrews's (1995) comparative trial of interventions to reduce problem behaviours in high-risk youth (parent-only groups, youth-only groups and a combined approach) found that whilst all three strategies produced short-term positive impacts on family conflict, youth groups were 
associated with higher rates of smoking and teacher reports of anti-social behaviour. Kumpfer and Alvarado (1998) argue that such iatrogenic effects indicate the need to reconsider the practice of aggregating high-risk youth in child-only interventions, and the importance of involving parents as well as children, so as to ensure the provision of positive adult role models (see also Dishion and Tipsord, 2011 on the importance of parental structure and monitoring as moderators of peer contagion).

However, less has been written about how group dynamics work in parenting programmes (or those involving both parents and young people) and how this might shape their delivery and receipt, particularly when interventions adopt a targeted approach. Studies of parenting interventions and support groups have found that the sharing and normalisation of experiences through interactions with other participants can be a key benefit which parents derive from their participation (Barlow and Stewart-Brown, 2006; Coombes et al., 2006; Mohr, 2004). But whilst the potential for negative or exclusionary group processes to operate in parenting groups has been acknowledged (Barlow and Stewart-Brown, 2006; Galinsky and Schopler, 1994; Grimshaw and Mc Guire, 1998; Mohr, 2004; Schultz et al., 1993), there has been little investigation of how such processes among parents might diminish programme effectiveness or produce harmful effects, nor how this might inform the design and group composition of parenting/family interventions. Prevention interventions which comprise tightly structured and timed sessions may face challenges in balancing the imperative to deliver activities as intended (fidelity) and the need to address participants' concerns or support needs (Byrnes et al., 2010), and such challenges may be particularly acute when families have high levels of support need (Coombes et al., 2006).

This paper reports the findings from an exploratory evaluation of the Strengthening Families Programme (SFP) 10-14 in Cardiff, Wales, UK which sought to address these challenges. The project was commissioned by policy makers in the Welsh Government to assess the potential of the SFP10-14 as a national programme for Wales, and had three key aims. First, to evaluate the Cardiff-based SFP10-14, from the perspective of participating families, programme facilitators and the co-ordinating staff. Second, to identify what mechanisms and resources needed to be in place for the programme to be introduced nationally across Wales. Third, to make recommendations regarding the design and content of a monitoring and evaluation framework for any such national rollout of the programme. This paper explores two key aspects of programme delivery which emerged during the analysis - the strategies used to recruit families into a universal prevention intervention, and the attempt to use the composition of groups of families attending the intervention (addressing the mix of families with challenges, and those from the general population) to maximise delivery fidelity, family engagement and satisfaction. The final section of the paper examines receipt of the programme by families and its acceptability to them.

\section{Background to the SFP10-14}

Drawing on a number of theoretical frameworks, including the bio-psychosocial, family process and resiliency models, the SFP10-14 focuses on family functioning, including communication between parents and children and parental skills, and helps young people to develop skills in relation to resisting peer pressure, stress management and goal setting (Molgaard et al., 2000). The SFP10-14 is a universal prevention intervention designed for groups of families with children aged ten to 14 in the general population, and comprises seven two-hour sessions (Molgaard et al., 2000). It is delivered through games, practical activities and videos. In the first hour parents and young people undertake separate activities. In the second hour they work together to practise and consolidate learning from hour 1. Details of the programme sessions and risk and protective factors addressed are outlined in Tables I and II. A series of four booster sessions can also be offered.

Several US schools-based trials have demonstrated the programme's ability to delay substance use initiation and reduce consumption levels and frequency among adolescents (Spoth et al., 2001, 2008). Culturally adapted versions of the SFP10-14 have also been produced for various ethnic groups in the USA, and other countries, including the UK (Allen et al., undated, 2007; 
Azziz-Baumgartner and Wilson, 2009; Brody et al., 2006; Kumpfer et al., 2008; Skärstrand et al., 2008). Research on the implementation of the SFP10-14 has considered aspects such as recruitment strategies (Spoth et al., 2007a), delivery models (Spoth et al., 2004, 2007b) and the links between implementation fidelity and participant engagement (Byrnes et al., 2010), but has not examined specific strategies to increase family engagement and enhance programme delivery through group composition strategies.

\section{Method}

The research adopted a mainly qualitative approach in order to understand the key elements of the approach taken to delivery of the SFP in Cardiff, and the experiences of families who had attended the programme. The author (who was independent of the programme delivery team) recruited participants into the study, and was responsible for data collection and analysis (three colleagues assisted with the running of the focus groups with families). Families taking part in the research had already agreed to attend the SFP, and they were free to choose whether or not they also participated in the research study without affecting their access to the programme. Semistructured interviews were conducted with the programme coordinating team. These examined the rationale for establishing the programme in Cardiff, delivery structures and organisation, the programme's target population and recruitment and engagement strategies. A focus group was

Table I Risk and protective factors addressed by the SFP10-14

\begin{tabular}{|c|c|c|}
\hline Session & Factors & $\begin{array}{l}\text { dressed } \\
\text { Risk }\end{array}$ \\
\hline Session 1 & $\begin{array}{l}\text { Positive future orientation, goal setting and } \\
\text { planning, supportive family involvement }\end{array}$ & $\begin{array}{l}\text { Demanding/rejecting behaviour, poor } \\
\text { communication skills }\end{array}$ \\
\hline Session 2 & $\begin{array}{l}\text { Age-appropriate parental expectations, } \\
\text { positive parent-child affect, empathy with } \\
\text { parents }\end{array}$ & $\begin{array}{l}\text { Harsh and inappropriate discipline, poor } \\
\text { child-parent relationship }\end{array}$ \\
\hline Session 3 & $\begin{array}{l}\text { Emotional management skills, family } \\
\text { cohesiveness }\end{array}$ & $\begin{array}{l}\text { Harsh, inconsistent, or inappropriate } \\
\text { discipline; poor communication of rules; } \\
\text { child aggressive or withdrawn behavior. }\end{array}$ \\
\hline Session 4 & $\begin{array}{l}\text { Youth reflective skills, empathy with } \\
\text { parents, pro-social family values }\end{array}$ & $\begin{array}{l}\text { Poor parental monitoring; poor, harsh, } \\
\text { inconsistent, or inappropriate discipline; } \\
\text { youth antisocial behaviors }\end{array}$ \\
\hline Session 5 & $\begin{array}{l}\text { Cohesive, supportive family environment; } \\
\text { consistent discipline; meaningful family } \\
\text { involvement; empathetic family } \\
\text { communication; social skills; peer refusal } \\
\text { skills }\end{array}$ & $\begin{array}{l}\text { Indulgent or harsh parenting style, family } \\
\text { conflict, negative peer influence }\end{array}$ \\
\hline Session 6 & $\begin{array}{l}\text { Positive parent-child affect, clear parental } \\
\text { expectations regarding substance use, } \\
\text { interpersonal social skills, peer refusal } \\
\text { skills }\end{array}$ & $\begin{array}{l}\text { Poor school performance, negative peer } \\
\text { influence }\end{array}$ \\
\hline Session 7 & $\begin{array}{l}\text { Positive parent-child affect, reinforcement } \\
\text { of risk reduction skills addressed in the } \\
\text { programme, reinforcement of protective } \\
\text { factors and youth assets }\end{array}$ & $\begin{array}{l}\text { Poorly managed adult stress, poor social } \\
\text { skills in youth }\end{array}$ \\
\hline $\mathrm{B} \sum_{1}^{\mathrm{B}}$ & $\begin{array}{l}\text { Pro-social peer interaction skills, effective } \\
\text { stress and coping skills }\end{array}$ & $\begin{array}{l}\text { Ineffective conflict management skills, } \\
\text { poorly managed adult stress }\end{array}$ \\
\hline $\begin{array}{l}\text { Booster } \\
\text { Session } 2\end{array}$ & $\begin{array}{l}\text { Conflict resolution skills, positive marital } \\
\text { interaction }\end{array}$ & $\begin{array}{l}\text { Peer conflict and aggression, hostile } \\
\text { family interactions }\end{array}$ \\
\hline $\begin{array}{l}\text { Booster } \\
\text { Session } 3\end{array}$ & $\begin{array}{l}\text { Cohesive, supportive family environment; } \\
\text { empathy with parents; consistent } \\
\text { discipline }\end{array}$ & $\begin{array}{l}\text { Harsh and inappropriate discipline, poor } \\
\text { child-parent relationship, poor } \\
\text { communication of rules }\end{array}$ \\
\hline $\begin{array}{l}\text { Booster } \\
\text { Session } 4\end{array}$ & $\begin{array}{l}\text { Positive marital interaction, family } \\
\text { cohesiveness, peer refusal skills }\end{array}$ & $\begin{array}{l}\text { Ineffective conflict management skills, } \\
\text { negative peer influence, inappropriate } \\
\text { parental expectations }\end{array}$ \\
\hline
\end{tabular}

Source: Molgaard et al. (2000) 
Table II Session topics

Parents

Using love and limits

Making house rules

Encouraging good behaviour

Using consequences

Building bridges

Protecting against substance misuse

Getting help for special family needs

Yor oople

$\mathrm{Ha} 2$ yoals and dreams

Appreciating parents

Dealing with stress

Following rules

Handling peer pressure I

Handling peer pressure II

Reaching out to others

Do

orting goals and dreams

Appreciating family members

Using family meetings

Understanding family values

Building family communication

Reaching goals

Putting it all together and graduation

Source: Molgaard et al. (2000)
Handling stress

Communicating when you don't agree

Reviewing love and limits skills

Reviewing how to help with peer

Pressure

Handling conflict

Making good friends

Getting the message across

Practicing our skills

Understanding each other

Listening to each other

Understanding family roles

Using family strengths

held with staff from partner agencies who had acted as programme facilitators to explore their experiences of delivering the SFP and the strengths and limitations of the delivery model used. Three pre-programme visits to families were observed in order to investigate how the coordinating team engaged with families prior to their attendance on the programme. Five programme sessions were observed to examine delivery (and the extent to which activities were delivered as intended) and families' response (including issues of group dynamics). Sessions observed comprised: Sessions 2 and 3 from a four-week booster programme in Autumn 2007, and Sessions 3, 4 and 7 from a seven-week programme, also in Autumn 2007. Each observation session included the family hour, and a mixture of parent/young people's activities were observed during the first hour. The sessions were selected so as to capture a cross-section of the programme's content (summarised in Table II), and allow sufficient time during the initial programme sessions for the researcher to meet with families and explain the purpose of the proposed data collection. As the aim of the observation was exploratory in nature, structured schedules were not used, but detailed notes were made, which were later subjected to a thematic analysis.

Four focus groups were held with families who had attended the programme (the same programmes as those observed by the researcher) to assess its receipt and acceptability. Separate groups were held with parents and young people. The author was also given access to routine data from the SFP10-14 Parent/Caregiver Survey Questionnaire (PCSQ) and Young Persons Survey Questionnaire (YPSQ) which families attending the programme are asked to complete. The exploratory aims of the research and limitations in the questionnaire data (which was only available in aggregated form, not for specific individuals) precluded a full-statistical analysis. Free text comments on the questionnaires which related to key things which participants had learnt were examined.

\section{Sample}

All four members of staff from the programme's coordinating team participated in interviews, and one joint follow-up interview was conducted. They comprised the programme coordinator, 
administrative assistant, Family Support Services Development Officer and a service manager. All 17 trained programme facilitators were invited to participate in a focus group, of whom 11 eventually took part. They represented seven of the 14 organisations involved in programme delivery (list below provides details of the 14 organisations involved in the delivery of SFP10-11 session, September 2007), and came from a range of professional backgrounds, including Youth Offending, Education Welfare, parenting support and substance misuse services:

- Cardiff CADT (including social workers, counsellors and support workers).

- National Children's Homes (NCH) Children and Youth Parenting Team.

- Barnardo's 5-15 Project.

- Cardiff YMCA Youth Service.

- Cardiff Council Youth Service.

- Cardiff Community Addictions Unit.

- South Wales Police.

- Llanrumney High School.

- Michaelston Community College.

- Llanrumney Healthy Living Centre.

- Cardiff Women's Aid.

- Cardiff Education Welfare Service.

- Newlink Wales.

- Cardiff Council Children's Services.

Parents and young people who participated in the research were drawn from a total of 61 families that had attended seven SFP in the city. Two sets of focus groups were held. For the first set of groups, families attending a four-week SFP booster programme were invited by the researcher to participate in the researc $\mathbb{}$ and provided with written information sheets. Four parents (three mothers and one fatt icr, and four children participated (representing six families in total). One parent who was unable to attend a focus group provided written feedback on their experiences. The second round of focus groups recruited participants from the cohort of families attending a seven-week programm (2) Problems were encountered with recruitment for these focus groups, despite attempts to remove barriers to attendance (such as providing a free crèche for young children not involved in the research). Recruitment was therefore broadened to include families who had attended previous programmes, and letters were written by the researcher to these families. Two mothers and two children participated in these groups, though another three had indicated they would be present. Participants had completed the seven-week programme but at different times.

Five of the six parents who took part in focus groups had been encouraged to attend the programme by practitioners who were working with their family, including school staff, a healthcare professional, an education welfare officer and a children's charity worker. One of these parents had already decided to attend after receiving a leaflet from school. The sixth participant had been encouraged to attend by a programme facilitator and advised that the programme would be a helpful way of preparing for parenting a teenager, but this was not in response to any specific difficulty. Data from PCSQ and YPSQ was available for a total of 56 families who had attended one of seven programme runs.

\section{Analysis}

Interviews and focus groups were audio-recorded (with participants' consent) and transcribed. A thematic content approach was adopted (Braun and Clarke, 2006) for the qualitative data (interview and focus group transcripts, free text responses from the PCSQ and YPSQ and 
observation notes from family visits and SFP sessions). Each data source was read several times by the author to achieve immersion in the data and key themes were identified which were then organised into an initial analytical framework. This framework was compared against headings in interview/focus group guides to ensure coverage of key research questions. The analytical framework was then transferred into NVivo, and transcripts and other data sources were read on screen and each section of text coded to relevant themes. Once this initial coding had been completed each of the themes was explored by reading all of the data coded to that theme. Further coding was undertaken, with some themes merged, and others added. The process was iterative and involved regularly returning to the data in its original context. The study's analytical framework is shown in Table III.

Table III Summary of analytical framework: themes discussed in this paper are shaded in grey

Origins, aims and goals

\begin{tabular}{|c|c|}
\hline Programme preparation and organisation & $\begin{array}{l}\text { Funding } \\
\text { Collaboration and multi agency working } \\
\text { Links with schools } \\
\text { Distinctiveness of Cardiff SFP } \\
\text { Facilitators } \\
\text { Organisational location } \\
\text { Training } \\
\text { Booster sessions } \\
\text { Monitoring and evaluation } \\
\text { Sustainability }\end{array}$ \\
\hline Engaging with families & $\begin{array}{l}\text { Who the programme is aimed at } \\
\text { Universalism and targeting } \\
\text { Engaging with families }\end{array}$ \\
\hline & $\begin{array}{l}\text { Pre-programme info } \\
\text { Practical support for parents } \\
\text { Retention and attrition } \\
\text { Support after programme }\end{array}$ \\
\hline Who attends & $\begin{array}{l}\text { Demand for programme } \\
\text { Fast access to programme }\end{array}$ \\
\hline & $\begin{array}{l}\text { Challenging youths in group settings } \\
\text { Mix of families } \\
\text { Motivation and need } \\
\text { Siblings attending } \\
\text { Problem families } \\
\text { Stigma }\end{array}$ \\
\hline Programme content & $\begin{array}{l}\text { Activities and games } \\
\text { Creeds } \\
\text { Cultural appropriateness } \\
\text { Age appropriateness } \\
\text { Appropriateness for different ethnic groups } \\
\text { DVDs } \\
\text { Incentives + prizes } \\
\text { Resources + handouts } \\
\text { Structure and pace }\end{array}$ \\
\hline Experiences of attending & $\begin{array}{l}\text { Families' hopes and expectations } \\
\text { Making sacrifice to come } \\
\text { What families liked }\end{array}$ \\
\hline & $\begin{array}{l}\text { Promoting programme to others } \\
\text { What happens after the programme }\end{array}$ \\
\hline Outcomes & $\begin{array}{l}\text { Families discover they are like others } \\
\text { Things that could be improved } \\
\text { Use of skills } \\
\text { What parents learnt } \\
\text { What YP learnt }\end{array}$ \\
\hline Future & National roll out \\
\hline
\end{tabular}




\section{Ethical issues}

Ethical approval for the research was obtained from the Cardiff University School of Social Sciences Research Ethics Committee (reference SREC/241). A number of ethical issues were raised by the project, including the importance of maintaining the confidentiality and anonymity of data provided by those taking part, and the involvement of children as participants.

All individuals who were invited to participate in the research were provided with an information sheet and, where appropriate, a letter of invitation. Young people were given an information sheet written in accessible language. These procedures were followed for interviews and focus groups and for observation of family visits/programme sessions. Advice was sought from colleagues with experience of undertaking research with teenage children and the information sheet was also given to a young person to seek their comments.

Sufficient time was allowed for potential participants to decide whether or not they wished to take part. Information sheets provided for families stressed that non-participation in the research would have no impact on their access to the SFP10-14. Before observing the programme the lead researcher also attended a programme session to explain to families what the research would involve and to answer any questions they had. All participants were asked to sign a consent form, including those who agreed to the researcher observing their family visit. Young people provided written assent, and their parents/caregivers also gave written consent for their children to take part.

Interviews with members of the programme coordinating team involved a very small number of individuals each of whom had a unique role. They were therefore potentially easily identifiable and the guarantees of anonymity which researchers typically offer participants could not be given. To address this issue members of the programme coordinating team were provided with a copy of the transcript from their interview to ensure that they were happy for the contents to be used in the research.

The focus groups with families did not ask participants to talk in detail about their personal lives or any problems that may have formed part of the reason for their attendance. However, parents/caregivers and young people did share personal stories, emotions and details of their life situation. It was important that such information was kept confidential and only used in an anonymised form. All staff involved who worked on the project had undergone enhanced checks by the Criminal Records Bureau. The focus group with young people was run by two or three researchers (at least one male and one female member of staff).

\section{Results}

The SFP10-14 was established in Cardiff by the Cardiff Alcohol and Drugs Team (CADT), based within the council's social services department. Programme sessions were delivered by facilitators from a partnership of 14 organisations, led by a full-time dedicated programme coordinator and supported by a Family Support Services Development Officer in CADT. Facilitators were released free of charge by their employers. The coordinator was responsible for preparation and planning activities. The development of the Cardiff SFP10-14 through a multi-agency partnership had brought together organisations in the fields of substance misuse, education and child welfare and family services, making new connections across these sectors:

[...] our decision was to attempt to recruit the widest interest. Because [drug and alcohol misuse] is such a cross cutting issue, it addresses everybody's agendas. And we thought "Is it possible to pull all those stakeholders into one group and then see if they want to play a part in delivering this service?". And that each of their representatives would be delivering the aims of their own organisation. Because preventing drug and alcohol difficulties was an aim for school staff, EWOs [education welfare officers], health visitors, social workers, voluntary organisations - it was in their aims. This was a way of them meeting their aims and also delivering this programme with no extra cost than the co-ordination and the facilitation. So that seemed to be an excellent way forward [...] (Coordinating team, interview 1).

PAGE 8 | JOURNAL OF CHILDREN'S SERVICES | VOL. xx NO. xx 2013 


\section{Recruitment and referral}

The programme delivery team had established the SFP10-14 with the aim of delivering it as a universal prevention intervention:

[...] the programme is described as a universal primary prevention intervention and I can't really emphasise enough how universal the programme is. It's not a programme for particularly high risk families, it's not a programme for particularly, families with any particular certain characteristics. (Coordinating team, interview 1)=

Interviewer: And is it for you, is it aimed at particular kinds of families or is there any kind of [?]

INT: Not at all [...] I think any family could vote with their feet, go on this and find it enormously helpful. It deals with such key communication issues for dealing with young adolescents. It's a fantastic resource for any family, so no, it's not about identifying problems, it's about any family strengthening themselves against future challenges, (Coordinating team, interview 3)=

However, the team had judged that such a programme was unlikely to attract large numbers of applications from families in the general population in its early stages of implementation. Initial recruitment therefore focused on receiving referrals from agencies who were already working with families, often those with higher level support needs in relation to parenting and family functioning:

Where we started was wanting to bring this programme to Cardiff as a prevention programme. Inevitably any type of parenting or family work programme tends to attract referrals from families with difficulties. Unfortunately that adds to the stigma of these types of programme but you have to start somewhere. So we started with a group of professionals who were inevitably working with families who were needing some support. So in the early days the mix of families tended to be more made up of a higher proportion of families with some difficulties (Coordinating team, interview 1).

The team had subsequently sought to widen the recruitment base for the SFP10-14. One important strategy had been the engagement of a broad cross-section of agencies (both in relation to referrals and involvement in programme delivery), with the aim of promoting the SFP as a family programme with broad relevance, rather than being focused narrowly on a particular set of problems/support needs. The team had also sought to promote the programme to the general population across the city, and to encourage families to apply to take part, emphasising that the SFP was for "any family" and not in any way limited to those families with problems, with the aim of de-stigmatising attendance. Engaging with parents and children via schools was an important aspect of this work:

[...] we're working almost exclusively now doing the programme through schools which gives us a real opportunity, doesn't it, to mainstream, if you like, the programme, to any family by working with the school rather than referrers [...] whose role it is to support some very challenging and very troubled families often. What we're attempting to do is support both but in a way that everyone gets the most out of it (Coordinating team, interview 5):

This strategy of "mainstreaming" included distributing leaflets to whole year groups of pupils, attending school events or speaking to parents when they came to pick up their children, as well as encouraging school staff to promote the programme and/or make referrals themselves. Through these strategies it was also hoped that families who attended the programme would generate "word of mouth" referrals. Over the course of the first six programmes (2005-2006), a total of 61 referrals were made to the SFP, with 25 self-referrals. In contrast, the four programmes running during April 2008-March 2009 received 28 referrals and 39 self-referrals.

Most families were referred to the SFP10-14 because of problems or support needs in relation to family functioning, child behaviour or school attendance. Interviewees suggested that where families self-referred it was less likely that they were experiencing significant difficulties, though it may have addressed parents' perceived needs, such as advice on how to parent teenagers and how to help young people to set positive goals.

Programme staff described engagement with families prior to their attendance on the programme as a key part of the recruitment process. The co-ordinator visited families once a referral/self-referral was received to provide information about the SFP and ascertain which

VOL. xx NO. xx $2013 \mid$ JOURNAL OF CHILDREN'S SERVICES | PAGE 9 
aspects of the programme might be attractive to families. Interviews, and observation of these meetings, suggested that in such meetings staff were attempting to "match the programme to the family" and to build a relationship with them. Interviewees emphasised that the programme did not judge families or examine deficits, but was concerned with strengths and solutions. Where it was not appropriate for a family to attend the programme (e.g. because a family had very high needs), SFP10-14 staff would signpost alternative sources of support. Home visits also allowed the coordinator to identify and discuss any challenges or needs which families might experience during the programme and how these could best be addressed.

Finally, steps had been taken to reduce practical barriers to attendance. This comprised up front reimbursement of families' travel expenses, organising free on-site play provision for younger siblings of children attending the SFP and providing refreshments for all family members:

[...] you have to think about every obstacle that people have to come to get on a programme like that. So there's the internal obstacles which is, "Is this going to be any help? Do I really want to sit in a room with my mother and father? Is it going to be embarrassing, is it going to be awkward and difficult?". So people need skilled help to overcome those personal ambivalent feelings about going on it in the first place. So that's absolutely key and the pre interviews that [the programme coordinator] carries out - and she's a very skilled communicator, help to break those barriers down. But then there's all the practical ones. You know, what do we do with the little ones if we're concentrating on the older ones and what do we do about the fact that this is tea time and children have to be fed? What do we do about transport, what do we do about money? All of those things have to be addressed in a way that makes this an attractive proposition both to the children and to parents. And so the preparation work is really, really important. It needs to be completely sensitively handled - non stigmatising, not implying in any way that people have been targeted because they've got problematic children. You know all of those kinds of things you have to be really, really careful about, and respectfully, genuinely deliver a service that breaks down all the obstacles to people attending. And having achieved that the levels of retention and engagement have been very high_(Coordinating team, interview 3)=

\section{Programme composition: "mixed families" approach}

Delivery of the programme used a "mixed families" approach. Groups of families who came together to receive the programme were purposively comprised of approximately 30 per cent who might present or experience challenges within a group setting and 70 per cent who would not. Such challenges included behavioural problems, learning difficulties and low literacy levels. This approach was a response to the delivery team's experience of running programmes comprised mainly of families with challenging behaviour and its potential to disrupt session activities and alienate other families, leading to higher attrition rates:

[...] what we've learnt is that it's useful for families with some challenges to come to the programme provided there's a blend of around seventy percent to thirty percent of families that don't have any particular difficulties or it, particularly with the youngsters, might present a challenge in a group setting. So for example if we've got a high proportion of young people who've been excluded from school or they're attending an inclusion unit usually that's because they've had difficulties in a group setting in school so they've been segregated. Now those difficulties won't disappear, they'll come back to the fore when they come to the Strengthening Families Programme because it's another group setting so we have to bear that in mind, we have to think about the welfare of the whole group and everyone's putting a big investment into this and the families [?], it's only right and proper that they get the best, get the most out of it that they possibly can. So what we now say is when we look at the makeup of the referrals to any particular programme we assess that quite carefully. [The programme coordinator] does home visits to every family and talks to the referrers in quite huge detail and will assess whether it's any particular, what the profile of any particular programme will be. So [we] try to create a situation where there's a mix of about seventy percent of the families where the youngsters won't present any particularly huge challenges to the group or the parents won't present any particularly huge challenges to the group and where there's a possibility amongst the other thirty percent that they may, (Coordinating team, interview 1):

[We are] looking at [...] a mix of high and low challenge families because if you had a programme with ten families that were all of exceptionally high need and very challenging it would be very difficult to run the programme. [...] for example one programme we had three children who came from the same inclusion unit. Now the reason they were in inclusion units was because they weren't working well in

PAGE 10 | JOURNAL OF CHILDREN'S SERVICES $\mid$ VOL. xx NO. xx 2013 
group settings so to pull those three who were in the same inclusion unit into a group setting met for a very challenging programme, (Coordinating team, interview 2):

The 30/70 split was designed to enable the tightly timed and highly structured sessions to be delivered effectively and enable adequate support to those families with higher needs/ challenges during the programme sessions. Members of the delivery team suggested that attending to group composition and employment of a dedicated coordinator were linked to the retention rates of around 85 per cent which were achieved (recruitment and retention levels are shown in Figure 1). Observation of programme sessions identified two main challenges to group dynamics which facilitators attempted to manage. First, disruptive or disengaged behaviour among young people:

I noticed that even at this early point in the second hour that some of the children were not always paying attention, and the "non lead" facilitators helped keep order (Fieldnotes, Booster session 3, family hour)=

Second, facilitators sometimes helped parents/carers and their children to work harmoniously during family activities:

In one group someone seemed to get hurt, and [name of parent] said something like "I knew this would happen" and then she took her son out of the room, closely followed by a number of facilitators. This seemed to underline the importance of having sufficient facilitators (Fieldnotes, 7 week session 3 , family hour):

At one point one of the mothers is talking to [name of facilitator] about the exercise. She (the mother) is talking about what it was like to do this activity (the shield) and that for teenagers, nothing is important. And [the facilitator] comes back by pointing out that yet the son in question has put forward his ideas about the values in his family,(Fieldnotes, SFP 7 week session, week 4).

A core driver of the 30/70 mixed families approach appeared to be a belief that it could help shape group dynamics and shared learning in positive ways, which were more closely aligned with programme values, thus allowing the programme to function as intended:

What tends then to happen is those [families with challenges] [...] tend to get pulled along in a positive way by those that haven't got a particular difficulty rather [than] it being the other way round. [...] I believe it's most helpful to families with perhaps higher levels of need to come to a programme where there's a reasonable mix of families with lower level need because $[\ldots]$ it enhances their experience and I think if they have a positive experience of learning then [pause] they're more likely to take something away from the programme. Whereas I think if we had [...] large concentrations of families with particular difficulties I think those families would as a group gain less. [...] What in simple terms what we want to do is pull people up rather than pull people back and a way of doing that is by having [...] a certain mix of families in the programme, (Coordinating team, interview 1)=

Figure 1 Programme recruitment and retention

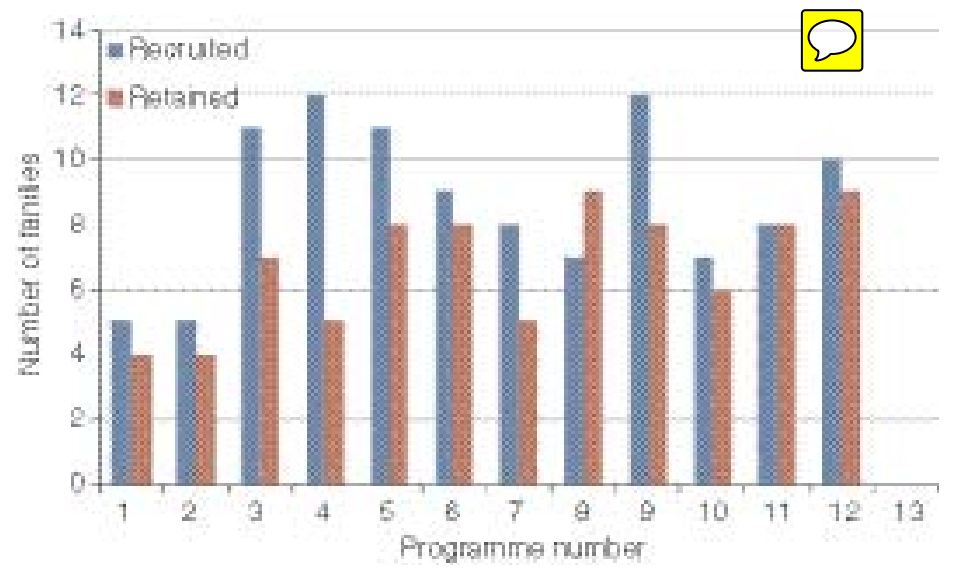

VOL. xx NO. xx $2013 \mid$ JOURNAL OF CHILDREN'S SERVICES $\mid$ PAGE 11 
Participant 1: And it's very difficult I think to get that balance, it's an unspoken and unwritten optimum level of, and I don't even know how to describe them, almost values, within the group, right across the group, so that for families having difficulties, they are almost kept buoyant by the ambient value, are you with me?

Participant: Yes.

Participant 2: There are more positive than negative ratio.

Participant 1: It keeps them afloat in the group dynamic which is really important. And then as a facilitator you can just carry that group through the process.

Participant 2: Because if you have all negatives then it is not a very successful, it's pulling them down. (Facilitators' focus group)=

This mix of families was also seen by programme staff as important in de-stigmatizing participation and communicating to participants that the SFP was a universal programme for all families, not targeted at those with problems. One facilitator in the focus group felt that by having mixed groups, the programme made a powerful statement to families who came to the programme that their peers were other families, rather than other families with problems:

Something I feel as a parenting worker, and that's my role, a big part of my role is boosting parents' self esteem and I was fortunate enough to facilitate a programme where this experience would have been learnt. But I think a danger of, or a risk of putting lots of families who have experienced a lot of difficulties together is you can compound their low self esteem, so they are thinking "These are my peers", and that's very difficult. But if you keep that mix, then they are like, "Actually these are my peers, my peers are just parents full stop", and I think that is again, really subtle but positive.

\section{Acceptability and receipt Parents}

High levels of acceptability were reported by parents who participated in focus groups. Participants described initially feeling nervous about attending the programme but that sessions took place in a relaxed atmosphere, making them feel welcome and comfortable. They had been encouraged to express opinions and different views had been respected. Some participants had been concerned that their parenting skills might be judged or criticised, but such fears were allayed and they believed that sessions had been delivered in a non-judgmental way. One reflected on the fact that the highly structured and fast moving pace of the programme sometimes cut short time for discussion of key issues, and this problem was also raised in the facilitators' focus group.

The support which participants gained from sharing (and thereby normalising) their problems and experiences with other parents was highlighted as important, and had sometimes led to new friendships being formed:

Int. 1: I found support and friendship.

Int. 2: Yeah.

Int. 1: um, with everyone, 'cause we can all talk to each other when we have our little breaks which is super. And we discuss each other's problems and what's going on and it's nice to know other people are there going through the same (Focus group 1)=

Int. 1: [...] it sort of made me realise, and more my daughter realise, that we're just like every other family. [...] That I'm not the only one that shouts and she's not the only one that misbehaves.

Int. 2: Yeah, yeah.

Interviewer: OK.

Int. 1: Everyone's the same.

Int. 2: Yeah.

PAGE 12 | JOURNAL OF CHILDREN'S SERVICES $\mid$ VOL. xx NO. xx 2013 
Int. 1: So you don't feel then isolated like you're the only one who has this.

Int. 1: Has bad kids (Parents' focus group 2).

But whilst the sharing and mirroring of experiences was important, these processes depended on being accepted by others as "normal parents" rather than participation in the programme only being defined around a set of explicit problems:

Int. 1: [...] it's good because you come into the group [...] [and] nobody knows anybody.

Int. 2: Yeah.

Int. 1: Nobody can judge anybody.

Int. 2: No, no [agreeing at same time as Int 1 talking].

Int. 1: Nobody knows what your problem is.

Int. 3: No.

Int. 1: 'Cause none of us ever discussed, you're just a normal person.

Int. 2: Mmm.

Int. 1: trying to bring up your child [...] who's got problems, but you're not being judged. No one's being judged.

Interviewer: Sure.

Int. 4: You can divulge as little or as much as you want to. (Parents' focus group 1)-

All focus group participants described positive outcomes from their attendance on the programme, particularly in relation to parental skills and family functioning. Improved communication and understanding between parents and their children was an important theme in both the focus groups and questionnaire responses. Parents said they were calmer, had learnt to listen more effectively and tried to understand their children's point of view. One felt that "I'm just calmer, so I don't jump down her throat straight away now. I can stop and listen" (Focus group 1). Another described how "[...] l listen to him [my son] more, he listens [...] to me more so [pause] it's better all round because we were always screaming and fighting and, you know, [...] I just weren't getting nowhere" (Focus group 2)- These changes had helped participants feel more confident and positive as parents. They described having acquired specific skills such as setting clear limits and consequences, expressing how they felt, and dealing with stressful situations at home in a calmer manner. Parents had continued to use at least some of the skills and insights gained on the programme over the longer term, sometimes with their other children (who had not been on the programme). Some had shared the knowledge and skills gained on the programme with friends.

Play provision for younger siblings of children attending the programme was highly valued. Several parents indicated that if it had not been available they could not have attended. It also meant that the whole family were involved and that younger children did not feel that they were being "dragged along" to an activity solely for the benefit of an older sibling. Provision of refreshments also made attending the programme easier and the meal break created a chance to speak to other parents and develop social networks.

\section{Young people}

Young people who participated in focus groups described how they had enjoyed creative activities involving drawing or making things, games involving physical activity, and activities during which they worked with their parent(s). It appeared that younger children had enjoyed the programme more. This included the acceptability of programme's "ground rules", the content and communication of key messages during sessions and the appeal of the prizes given out. Participants in FG1 suggested a number of changes that could be made to the programme, including training peers as facilitators whom they felt would be better able to communicate with 
young people on issues such as resisting peer pressure. Most of the young people said that they had not known what to expect from the programme and felt nervous before the first session, and some held negative expectations of what the programme might be like:

JS: And when you first came on the first night, what were you expecting, d' you think?

Int1: Um, I was a bit nervous because I didn't know who would be there, and, I didn't.

Int2: I thought my sister was going to come in [?] my sister would come in and she would do my head in and l'd end up getting sent home for punching her in the face.

JS: OK, so you were a bit nervous because you didn't know who was going to be coming [Int1: Yeah] and you thought your sister would be there. OK. So were you a bit worried then that that might happen if she was here?

[silence]

JS: So if you look back then, so what did you think was actually going to happen in the programme? What were your sort of expectations? What were you thinking it would be like?

Int 1: I was thinking that you just like sit down the whole time and just listen to what they have to say. But it wasn't, it was like fun games and [you] got to discuss what you wanted to say, with the people that you met there and the teachers.

JS: OK. And how about you? What were you expecting on first night?

Int 2: I was going to get sent home (Focus group 2)=

Participants had made new friends and this was one of the most important outcomes from their attendance:

Int 1: Um, it was interesting and fun, because you would think it would take like ages to like get to know them and everything, but you - once you started talking, you're sort of friends and everything, so [...]

JS: So they became your friends, did they?

Int 1: Yeah.

Interviewer: And how about you - did you make new friends, or was it just the people that you already knew?

Int 2: I made new friends, because none of the people [?] [...] The only people here I really knew were [names of participants] and the rest of the, as soon as you got talking to them it was like you'd known them for ages. (Focus group 2)=

Data from the focus groups and YPSQ (summarised in list below) indicated evidence of learning directly related to programme content. Young people talked about the sessions in which they had learnt peer pressure resistance skills and one focus group participant described having used them to avoid being drawn into shoplifting - "Yesterday X said 'Oh let's go and get [steal] something from the shop' and I said 'No'". In a later part of the discussion the participant described some of the specific peer pressure resistance techniques which he had learnt and used. Other skills or awareness gained by young people included knowledge about the dangers of taking drugs, how to deal with stress, the importance of setting goals for the future and acquiring better communication skills. A number of focus group participants had experienced changes in family life since attending the programme (at least in the short term), with improved understanding and communication being a key theme. One participant felt that her mother had begun to listen to her, whilst another described how a sense of mutual understanding between her and her father had developed during the programme

(1) Stress:

- handling stress;

- the most valuable thing I have learned during this programme is to talk calmly to adults when something has annoyed me; 
- $\quad$ stress and peer pressure;

- make sure that I do not backchat and do not go mad, just stay calm;

- how to deal with stress; and

- to learn to control my temper and give compliments.

(2) Peer pressure:

- $\quad$ peer pressure and reaching my goals;

- bullying, peer pressure, suggest another route;

- peer pressure;

- I learnt and understand more about peer pressure;

- learning to deal with peer pressure;

- to deal with peer pressure;

- how to handle peer pressure; and

- how to handle peer pressure, obeying rules and knowing that my mum has feelings too.

(3) Family relationships:

- $\quad$ not to argue with my parents;

- the importance of spending time with my family;

- respect my parents;

- doing the family tree and showing that we care about each other;

- learning that children and their parents can be friends;

- to listen to my parent more, have family meetings and resist peer pressure;

- working together and being friends and to be good;

- how much my family love me and would do anything for me;

- communicating with my mum;

- to listen to my mum more often and do what she tells me to do;

- never keep something important to myself, always tell someone to see if they can help with my problem;

- getting to play cards with my dad;

- that even if my parents and me are having a row I now know it is natural and we are still best friends and we still love each other; and

- I have learnt to respect my parents' point of view and to say no to doing bad things.

(4) Alcohol and drugs:

- not to take drugs or alcohol at school or anywhere else; and

- not to take drugs and alcohol and how to handle peer pressure.

(5) Goals:

- reaching my goals, the reflection exercise, suggest another route, peer pressure;

- to make sure that I don't do anything stupid at all; to look after me!; and

- I learned how to do things I don't want to do and how to handle peer pressure.

(6) Rules:

- learning that rules are there for a reason and building a better relationship with my mum; 
- learning that rules are there for my own safety; and

- learning about right and wrong and I have enjoyed spending time with you all.

(7)

Intervie And then you said here [on the drawing], "made my mum understand me more", so how did that kind of work?

Int: Um, [pause] don't know, [pause] she just listens to me now (Focus group 1).

Interviewer: And you said it [the programme] helped in the end?

Int: Me and my dad understood each other more (Focus group 1)=

\section{Discussion}

Well-designed, theory-based family interventions have an important role to play in the prevention of substance misuse among young people. But the extent to which efficacious interventions can achieve effectiveness in real-world settings depends on a number of factors (or moderators) including programme reach, recruitment strategies, implementation quality and adoption by organisations (Glasgow et al., 2003). Many programmes have reported challenges in engaging parents and families to participate (Dusenbury, 2000), yet evaluation studies do not always fully address the theoretical or empirical aspects of recruitment and retention (Heinrichs et al. , 2005). This paper has sought to map out how one delivery team addressed the challenges of recruiting parents and young people into a universal prevention intervention and the ways in which they harnessed group composition with the aim of enhancing the quality of programme implementation, maximising the acceptability and value of the programme to families and promoting interaction between participants which supported programme values and intended psycho-social processes.

As an exploratory study involving a small number of participants it has a number of limitations. In ways which mirror the topic of interest, and despite significant attempts to engage families in the study, focus groups suffered from low levels of participation, and it cannot be assumed that the views of those who participated are typical of all the families participating in the SFP in Cardiff. Whilst the findings indicate the potential value of promoting prevention interventions to the whole population and of managing group dynamics in such programmes, the study was not designed to measure the effectiveness of particular recruitment approaches on participation levels, nor to assess the extent to which group composition strategies impacted on short- or long-term intended outcomes for families.

However, the findings indicate that the programme had succeeded in recruiting and retaining significant numbers of families and that it had achieved high levels of acceptability. The promotion of the SFP as a universal family programme appeared to have significant potential both in terms of engaging with families with differing levels of support needs (or risk behaviours), and framing participation to potential participants in ways which avoided stigmatisation or labelling. As Spoth et al. (2007c) have argued, "universal intervention strategies can provide an avenue for reaching at least some higher-risk youth, while avoiding iatrogenic effects sometimes observed when high-risk youth are grouped together for intervention" (p. 401).

The strategies adopted in relation to group composition also appeared to have a number of strengths in relation to promoting positive socialisation processes, the ability to deliver the programme as intended and the extent to which families' support needs could be met. To some extent the "30/70" mix of families with and without challenges responds to the well-documented problems of bringing together groups of high-risk young people and the potential for harmful peer learning processes, negative impacts on self-esteem and disruption to programme activities (Coombes et al., 2006; Dishion and Tipsord, 2011; Kumpfer and Alvarado, 1998; Wiggins et al., 2009). But although the SFP sought to engage families with a range of support need levels (e.g. in relation to parenting) the 30/70 mix was specifically concerned with challenges families might experience/present within a group setting and how these could be managed to optimise programme delivery quality. It was therefore primarily a feature of the

PAGE 16 | JOURNAL OF CHILDREN'S SERVICES $\mid$ VOL. xx NO. xx 2013 
delivery of the programme rather than a way of shaping which families were to be recruited. This approach also highlights the importance of attending to how group dynamics and socialisation might operate when both parents and children attend an intervention, which has received relatively little attention by researchers. The literature on parenting interventions has identified that peer support, and a process of "mirroring" through which individuals normalise their own experiences by hearing others share similar perspectives can be important aspects of parenting programmes (Barlow and Stewart-Brown, 2006), and these themes emerged strongly in the parents' accounts in this study. Research in the field of youth peer contagion has identified that deviancy training in programs may occur during unstructured activities (e.g. during breaks), and that adult supervision and structuring of "peer interactions" can moderate peer contagion and promote pro-social norms (Dishion et al., 2002; Dishion and Tipsord, 2011).

But we cannot simply assume that the iatrogenic effects of bringing together groups of young people with challenges will always be cancelled out by also involving their parents, who themselves will form part of a group with its own norms and socialisation processes. Aspects of parenting (such as supervision and monitoring) which protect against peer contagion (Dishion etal., 2011) (and which parent component of programmes such as the SFP seek to strengthen) could be shaped in a number of ways when groups of parents (and families) are brought together. Offering these programmes to families with a range of experiences (rather than narrowly defined groups of families with problems or identified support needs), as was the case in this study, might help reinforce mutual support and mirroring in positive ways that are more closely aligned with programme goals and values, and help prevent peer contagion. The importance of group dynamics within parenting programmes (in terms of their value for parents, and how these in turn might interact with components delivered to young people) suggests the need for practitioners to pay close attention to such dynamics, as well as whether core activities are delivered as intended.

Group norms and interaction have the potential to shape the extent to which interventions successfully promote the adoption of pro-social norms and communication by families, including the practising of the skills taught during programme sessions. As Gifford-Smith et al. (2005) have suggested in relation to youth-based interventions, examining how to reduce harmful peer influence is important, and aspects such as group composition might be harnessed as part of the design of interventions such as the SFP to help enable programmes processes to take place as intended. Implementation is more than the delivery of programme materials, and recruitment processes and group dynamics merit close attention, especially if participants bring high levels of challenges to a group. latrogenic effects may be less to do with actual programme activities, and more to do with the contexts in which they take place, including "components that most therapists consider incidental or unimportant" (Dishion et al., 2002; Dishion and Tipsord, 2011).

Prevention interventions such as the SFP10-14 which contain highly structured and tightly timed sessions can present challenges in relation to the need to cover key activities whilst also meeting the support needs of families, and providing opportunities for participants to discuss their experiences. For instance, a study of the SFP10-14 examining the relationship between delivery fidelity and family engagement found that higher levels of adherence resulted in lower levels of satisfaction among parents, because "To obtain high Adherence scores, health educators were often required to limit discussions to implement all programme activities" (Byrnes et al., 2010). The authors note that "A delivery challenge exists for the parent sessions in finding ways to cover all program activities while allowing participants to engage in mutually supportive behaviour". And research by Hill et al. (2007) on adaptations made by facilitators delivering the SFP10-14 found that the majority of changes (such as omitting or altering activities) was due to running out of time. The results from this study suggest that delivering the programme to mixed groups of families enabled appropriate support to be given to individuals with higher level support needs, and provided a way of managing group dynamics which enabled programme sessions to be delivered as intended. However, the pace of programme sessions and the limited time for discussion was still an issue for one parent participant, and was also raised in the facilitators' focus group.

Further research is needed to evaluate the acceptability of this "mixed families" approach, the extent to which it impacts on programme reach and delivery fidelity, and whether such changes 
translate into long-term impacts on key risk and protective factors, which have been found in previous large-scale evaluations of the programme. However, the study raises important issues about the implementation of family-based prevention interventions, and how recruitment processes and group dynamics can shape implementation processes. A randomised controlled trial of the SFP10-14 using the key elements of the delivery approach examined in this paper is currently ongoing, incorporating an embedded process evaluation to examine the important links between recruitment, programme delivery and outcomes for families.

\section{Implications for practice}

- A universal intervention strategy has significant potential in terms of engaging with families with differing levels of support needs and framing participation to potential participants in ways that avoid stigmatisation.

- The iatrogenic effects of bringing together groups of young people with challenges is not necessarily cancelled out by also involving their parents.

- Offering programmes to families with a range of experiences (rather than only those with identified support needs) might help reinforce mutual support and mirroring in ways that are aligned with programme goals and values, and help prevent peer contagion.

- Practitioners need to pay close attention to group dynamics within parenting programmes, as well as whether core activities are delivered as intended.

\section{Notes}

1. In total, 11 families were recruited to the programme itself, of whom eight attended most or all of the sessions.

2. Eight families were recruited for this programme, of whom five attended at least five of the programme sessions.

\section{References}

Al-Halabi Diaz, S., Secades-Villa, R., Perez, J., Fernandez-Hermida, J., Garcia-Rodriguez, O. and Crespo, J. (2006), "Family predictors of parent participation in an adolescent drug abuse prevention program", Drug Alcohol Review, Vol. 25, pp. 327-31.

Allen, D., Coombes, L. and Foxcroft, D. (undated), Preventing Alcohol and Drug Misuse in Young People: Adaptation and Testing of the Strengthening Families Programme 10-14 (SFP10-14) for Use in the United Kingdom, School of Health and Social Care, Oxford Brookes University, Oxford, 68pp.

Allen, D., Coombes, L. and Foxcroft, D. (2007), "Cultural accommodation of the Strengthening Families Programme 10-14: UK phase I study”, Health Education Research, Vol. 22 pp. 547-60.

Azziz-Baumgartner, C. and Wilson, L. (2009), "Applying a model of program adaptation to the Familias Fuertes parent/adolescent educational intervention for Latino immigrant families in the rural south", Southern Online Journal of Nursing Research, Vol. 9, p. 7.

Barlow, J. and Stewart-Brown, S. (2006), "Understanding parenting programmes: parents' views", Primary Health Care Research and Development, Vol. 2, pp. 117-30.

Bayer, J.K., Hiscock, H., Morton-Allen, E., Ukoumunne, O.C. and Wake, M. (2007), "Prevention of mental health problems: rationale for a universal approach", Archives of Disease in Childhood, Vol. 92 « pp. 34-8.

Botvin, G. and Griffin, K. (2007), "School-based programmes to prevent alcohol, tobacco and other drug use”, International Review of Psychiatry, Vol. 19, pp. 607-15.

Braun, V. and Clarke, V. (2006), "Using thematic analysis in psychology”, Qualitative Research in Psychology, Vol. 32,pp. 77-101.

Brody, G., Murny, V., Kogan, S., Gerrard, M., Gibbons, F. and Molgaard, V. otal., (2006), "The strong African American families program: a cluster-randomized prevention trial of long-term effects and a mediational model", Journal of Consulting and Clinical Psychology, Vol. 74. pp. 356-66. 
Byrnes, H., Miller, B., Aalborg, A., Plasencia, A. and Keagy, C. (2010), "Implementation fidelity in adolescent family-based prevention programs: relationship to family engagement", Health Education Research, Vol. 25, pp. 531-41.

Cho, H., Hallfors, D. and Sanchez, V. (2005), "Evaluation of a high school peer group intervention for at-risk youth”, Journal of Abnormal Child Psychology, Vol. 33, pp. 363-74.

Coombes, L., Allen, D., Marsh, M. and Foxcroft, D. (2006), Implementation of the Strengthening Families Program (SFP) 10-14 in Barnsley: The Perspectives of Facilitators and Families, Oxford Brookes University, Oxford.

Cuijpers, P. (2003), “Three decades of drug prevention research”, Drugs=Education Prevention and Policy, Vol. 10, pp. 7-20.

Dishion, T. and Andrews, D. (1995), "Preventing escalation in problem behaviors with high-risk young adolescents - immediate and 1-year outcomes", Journal of Consulting and Clinical Psychology, Vol. 63, pp. 538-48.

Dishion, T. and Tipsord, J. (2011) "Peer contagion in child and adolescent social and emotional development”, Annual Review of A Plogy, Vol. 62, pp. 189-214.

Dishion, T., Bullock, B. and Granic, I. (2002), "Pragmatism in modeling peer influence: dynamics, outcomes, and change processes", Development and Psychopathology, Vol. 14, pp. 969-81.

Dumka, L., Camille, A., Roosa, M. and Stoerzinger, H. (1997), "Recruitment and retention of high-risk families into a preventive parent training intervention", The Journal of Primary Prevention, Vol. 18, pp. 25-39.

Dusenbury, L. (2000), "Family-based drug abuse prevention programs: a review", The Journal of Primary Prevention, Vol. 20, pp. 337-52.

Fox, D., Gottfredson, D., Kumpfer, K. and Beatty, P. (2004), "Challenges in disseminating model programs: a qualitative analysis of the strengthening Washington DC families program”, Clinical Child and Family Psychology Review, Vol. 7, pp. 165-76.

Foxcroft, D and Lowe, G. (1997), "Adolescents' alcohol use and misuse: the socializing influence of perceived family life", Drug-Education Prevention and Policy, Vol. 4, pp. 215-29.

Galinsky, M. and Schopler, J. (1994), "Negative experiences in support groups”, Social Work in Health Care, Vol. 20, pp. 77-95.

Garmiene, A., Žemaitiene, N. and Zaborskis, A. (2006), "Family time, parental behaviour model and the initiation of smoking and alcohol use by ten-year-old children: an epidemiological study in Kaunas, Lithuania", BMC Public Health, Vol. 6. p. 287.

Gifford-Smith, M., Dodge, K., Dishion, T. and McCord, J. (2005), "Peer influence in children and adolescents: crossing the bridge from developmental to intervention science", Journal of Abnormal Child Psychology, Vol. 33, pp. 255-65.

Glasgow, R., Lichtenstein, E. and Marcus, A. (2003), "Why don't we see more translation of health promotion research to practice? Rethinking the efficacy-to-effectiveness transition", American Journal of Public Health, Vol. 93, pp. 1261-7.

Gottfredson, D., Kumpfer, K., Polizzi-Fox, D., Wilson, D., Puryear, V. and Beatty, P. ot at.,(2006), "The ștrengthening Washington D.C. families project: a randomized effectiveness trial of family-based prevention", Prevention Science, Vol. 7\&pp. 57-74.

Grimshaw, R. and Mc Guire, C. (1998), Evaluating Parenting Programmes: A Study of Stakeholders' Views, National Childrens' Bureau and Joseph Rowntree Foundation, London.

Guyll, M., Spoth, R. and Redmond, C. (2003), "The effects of incentives and research requirements on participation rates for a community-based preventive intervention research study", Journal of Primary Prevention, Vol. 24, pp. 25-41.

Heinrichs, N. (2006), "The effects of two different incentives on recruitment rates of families into a prevention program”, The Journal of Primary Prevention, Vol. 27, pp. 345-65.

Heinrichs, N., Bertram, H., Kuschel, A. and Hahlweg, K. (2005), "Parent recruitment and retention in a universal prevention program for child behavior and emotional problems: barriers to research and program participation", Prevention Science, Vol. 6. pp. 275-86. 
Highet, G. (2005), "Alcohol and cannabis: young people talking about how parents respond to their use of these two drugs", Drugs-Education Prevention and Policy, Vol. 12 pp. 113-24.

Hill, L., Maucione, K. and Hood, B. (2007), “A focused approach to assessing program fidelity”, Prevention Science, Vol. 8, pp. 25-34.

Hiscock, H., Bayer, J., Price, A., Ukoumunne, O., Rogers, S. and Wake, M. (2008), "Universal parenting programme to prevent early childhood behavioural problems: cluster randomised trial", British Medical Journal, Vol. 336, pp. 318-21.

Hogue, A., Liddle, H., Becker, D. and Johnson-Leckrone, J. (2002), "Family-based prevention counseling for high-risk young adolescents: immediate outcomes", Journal of Community Psychology, Vol. 30, pp. 1-22.

Kumpfer, K. (1998), "Selective prevention interventions: the Strengthening Families Program", in Etz, K., Robertson, E. and Ashery, R. (Eds), Drug Abuse Prevention through Family-Based Intervention: Future Research, Research Monograph, No. 177, NDD

Kumpfer, K. and Alvarado, R. (1998), "Effective family strengthening interventions", Juvenile Justice Bulletin.

Kumpfer, K., Pinyuchon, M., de Melo, A. and Whiteside, H. (2008), "Cultural adaptation process for international dissemination of the Strengthening Families Program", Evaluation and the Health Professions, Vol. 31 pp. 226-39.

Mihalic, S. and Irwin, K. (2003), "Blueprints for violence prevention: from research to real-world settings factors influencing the successful replication of model programs", Youth Violence and Juvenile Justice, Vol. 1 pp. 307-29.

Mohr, W. (2004), "Surfacing the life phases of a mental health support group", Qualitative Health Research, Vol. 14 , pp. 61-77.

Molgaard, V., Spoth, R. and Redmond, C. (2000), "The Strengthening Families Program: for parents and youth 10-14", Juvenile Justice Bulletin.

Moore, G., Rothwell, H. and Segrott, J. (2010), "An exploratory study of the relationship between parental attitudes and behaviour and young people's consumption of alcohol", Substance Abuse Treatment Prevention and Policy, Vol. 5.

Offord, D. (2000), "Selection of levels of prevention", Addictive Behaviors, Vol. 25, pp. 833-42.

Offord, D., Kraemer, H., Kazdin, A., Jensen, P. and Harrington, R. (1998), "Lowering the burden of suffering from child psychiatric disorder: trade-offs among clinical, targeted, and universal interventions", Journal of the American Academy of Child and Adolescent Psychiatry, Vol. 37 pp. 686-94.

Palinkas, L., Atkins, C., Miller, C. and Ferreira, D. (1996), "Social skills training for drug prevention in high-risk female adolescents", Preventive Medicine, Vol. 25, pp. 692-701.

Redmond, C., Spoth, R. and Trudeau, L. (2002), "Family-and community-level predictors of parent support seeking", ool. 30, pp. 153-71.

Redmond, C., Spoth, R., Shin, C. and Hill, G. (2004), "Engaging rural parents in family-focused programs to prevent youth substance abuse", The Journal of Primary Prevention, Vol. 24 \&p. 223-42.

Rose, G. (1992), The Strategy of Preventive Medicine, Oxford University Press, Oxford.

Sanders, M., Turner, K. and Markie-Dadds, C. (2002), "The development and dissemination of the triple p-positive parenting program: a multilevel, evidence-based system of parenting and family support", Prevention Science, Vol. 3, pp. 173-89.

Schultz, C., Schultz, N., Bruce, E. and Smyios, K (1993), "Psychoeducational support for parents of children with intellectual disability: an outcome study", International Journal of Disability, Development and Education, Vol. 40, pp. 110-9.

Secrest, L., Shana, L., Armistead, S., Wyckeff, d W Williams, W. and Kotchick, B. (2005), "The parents matter! Program: building a successful investigator-community partnership", Journal of Child and Family Studies, Vol. 13, pp. 35-45.

Shortt, A., Hutchinson, D., Chapman, R. and Toumbourou, J. (2007), "Family, school, peer and individual influences on early adolescent alcohol use: first-year impact of the fesilient families programme", Drug and Alcohol Review, Vol. 26, pp. 625-34. 
Skärstrand, E., Larsson, J. and Andréasson, S. (2008), "Cultural adaptation of the Strengthening Families Programme to a Swedish setting", Health Education, Vol. 108, pp. 287-300.

Skärstrand, E., Bränström, R., Sundell, K., Källmén, H. and Andréassen, S. (2009), "Parental participation and retention in an alcohol preventive family-focused programme", Health Education, Vol. 109, pp. 384-95.

Spoth, R. and Redmond, C. (2000), "Research on family engagement in preventive interventions: toward improved use of scientific findings in Primary prevention practice", The Journal of Primary Prevention, Vol. 21, pp. 267-84.

Spoth, R. and Redmond, C. (2002), "Project family prevention trials based in community-university partnerships: toward scaled-up preventive interventions", Prevention Science, Vol. 3, pp. 203-21.

Spoth, R., Kavanagh, K. and Dishion, T. (2002), "Family-centered preventive intervention science: toward benefits to larger populations of children, youth, and families", Prevention Science, Vol. 3, pp. 145-52.

Spoth, R., Redmond, C. and Shin, C. (2001), "Randomized trial of brief family interventions for general populations: adolescent substance use outcomes 4 years following baseline", Journal of Consulting and Clinical Psychology, Vol. 69, pp. 627-42.

Spoth, R., Greenberg, M., Bierman, K. and Redmond, C. (2004), "PROSPER community-university partnership model for public education systems: capacity-building for evidence-based, competencebuilding prevention", Prevention Science, Vol. 5 pp. 31-9.

Spoth, R., Clair, S., Greenberg, M., Redmond, C. and Shin, C. (2007a), "Toward dissemination of evidencebased family interventions: maintenance of community-based partnership recruitment results and associated factors", Journal of Family Psychology, Vol. 21 pp. 137-46.

Spoth, R., Guyll, M., Lillehoj, C., Redmond, C. and Greenberg, M. (2007b), "Prosper study of evidencebased intervention implementation quality by community-university partnerships", Journal of Community Psychology, Vol. 35, pp. 981-99.

Spoth, R., Randall, G., Trudeau, L., Shin, C. and Redmond, C. (2008), "Substance use outcomes $5 \frac{1}{2}$ years past baseline for partnership-based, family-school preventive interventions", Drug and Alcohol Dependence, Vol. 96, pp. 57-68.

Spoth, R., Redmond, C., Shin, C., Greenberg, M., Clair, S. and Feinberg, M. (2007c), "Substance-use outcomes at 18 months past baseline - The PROSPER community-university partnership trial", American Journal of Preventive Medicine, Vol. 32, pp. 395-402.

Velleman, R. (2009), Alcohol Prevention Programmes: A review of the literature for the Jospeh Rowntree Foundation (Part Two), Jospeph Rowntree Foundation, York.

Velleman, R. and Templeton, L. (2007), "Substance misuse by children and young people: the role of the family and implications for intervention and prevention", Paediatrics and Child Health, Vol. 17 kp pp. 25-30.

Wiggins, M., Bonell, C., Sawtell, M., Austerberry, H., Burchett, H. and Allen, E. et al., (2009), "Health outcomes of youth development programme in England: prospective matched comparison study", British Medical Journal, Vol. 339.

\section{About the author}

Jeremy Segrott PhD is a Research Fellow in Public Health at Cardiff University. His research is concerned with the prevention of alcohol misuse by young people, including the role of parents and families. He is currently involved in a randomised controlled trial of the Strengthening Families Programme (10-14), including leading the study's process evaluation. Jeremy Segrott can be contacted at: SegrottJ@Cardiff.ac.uk 


\section{AUTHOR QUERY FORM}

JOURNAL: JCS

VOL/ISSUE NO:

ARTICLE NO: 160489

ARTICLE TITLE: Recruitment and group composition strategies for family-based substance misuse prevention interventions: an exploratory evaluation

\section{AUTHORS: Jeremy Segrott}

During preparation of the above paper the following queries have arisen.

\begin{tabular}{|c|c|c|}
\hline NO. & Query & Author's Reply \\
\hline Q1 & $\begin{array}{l}\text { Please confirm change of (Secrest, 2005) to (Secrest et al., 2005) as per the } \\
\text { reference list in sentence "influential individuals in the community to ple } \\
\text { endorsements of programmes". }\end{array}$ & \\
\hline Q2 & $\begin{array}{l}\text { Please confirm change of "YPSQ" to "PCSQ" is the sentence "and } \\
\text { group transcripts, free text responses from the" is correct. }\end{array}$ & \\
\hline Q3 & $\begin{array}{l}\text { Reference "Dishion et al. (2011)" not listed in references. Please provide } \\
\text { complete publication details to add in the reference lis e delete text } \\
\text { citation. }\end{array}$ & \\
\hline Q4 & $\begin{array}{l}\text { Please provide issue number in reference Al-Halabi Diaz et al. (2006), Allen et } \\
\text { al. (2007), Barlow and Stewart-Brown (2006), Bayer et al. (2007), Botvin and } \\
\text { Griffin (2007), Braun and Clarke (2006), Byrnes et al. (2010), Cho et al. } \\
\text { (2005), Cuijpers (2003), Dishion and Andrews (1995), Dishion and Tipsord } \\
\text { (2011), Dishion et al. (2002), Dumka et al. (1997), D bury (2000), Fox et } \\
\text { al. (2004), Foxcroft and Lowe (1997), Galinsky and (1994), Gifford- } \\
\text { Smith et al. (2005), Glasgow et al. (2003), Guyll et al. (2003), Heinrichs } \\
\text { (2006), Heinrichs et al. (2005), Highet (2005), Hill et al. (2007), Hiscock et al. } \\
\text { (2008), Hogue et al. (2002), Kumpfer et al. (2008), Mihalic and Irwin (2003), } \\
\text { Mohr (2004), Offord (2000), Offord et al. (1998), Palinkas et al. (1996), } \\
\text { Redmond et al. (2004), Sanders et al. (2002), Schultz et al. (1993), Secrest et } \\
\text { al. (2005), Shortt et al. (2007), Skärstrand et al. (2008), Skärstrand et al. } \\
\text { (2009), Spoth and Redmond (2000), Spoth and Redmond (2002), Spoth et } \\
\text { al. (2002), Spoth et al. (2001), Spoth et al. (2004), Spoth et al. (2007a), Spoth } \\
\text { et al. (2007b), Spoth et al. (2008), Spoth et al. (2007c), Velleman and } \\
\text { Templeton (2007). }\end{array}$ & \\
\hline
\end{tabular}




\section{AUTHOR QUERY FORM}

JOURNAL: JCS

VOL/ISSUE NO:

ARTICLE NO: 160489

ARTICLE TITLE: Recruitment and group composition strategies for family-based substance misuse prevention interventions: an exploratory evaluation

AUTHORS: Jeremy Segrott

During preparation of the above paper the following queries have arisen.

\begin{tabular}{|c|c|c|}
\hline NO. & Query & Author's Reply \\
\hline Q5 & $\begin{array}{l}\text { Please provide issue number and if this is not a one page article please } \\
\text { provide last page in reference Azziz-Baumgart and Wilson (2009), } \\
\text { Garmiene et al. ( }) \text {. }\end{array}$ & \\
\hline Q6 & $\begin{array}{l}\text { Please provide remaining authors names and issue number in reference } \\
\text { Brody et al. (2006), Gottfredson et al. (2006). }\end{array}$ & \\
\hline Q7 & $\begin{array}{l}\text { Please provide city location of the publisher and page range in reference } \\
\text { Kumpfer (19) }\end{array}$ & \\
\hline Q8 & $\begin{array}{l}\text { Please provide further publication details for the reference Kur } \\
\text { Alvarado (1998), Molgazud and }\end{array}$ & \\
\hline Q9 & $\begin{array}{l}\text { Please provide issue number and page range in reference } \\
\text { (2010). }\end{array}$ & \\
\hline Q10 & $\begin{array}{l}\text { Please provide journal title ar } \\
\text { (2002). }\end{array}$ & \\
\hline Q11 & $\begin{array}{l}\text { Please provide remaining authors names, iss } \\
\text { reference Wiggins et al. (2009). }\end{array}$ & \\
\hline
\end{tabular}

